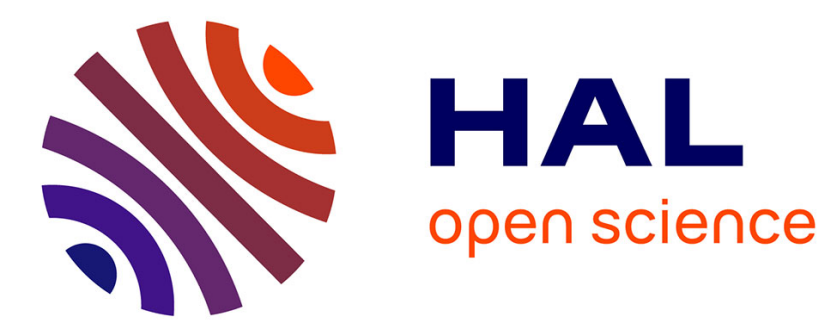

\title{
Experimental and numerical aspects of adiabatic shear in a 4340 steel
}

\author{
B. Deltort
}

\section{To cite this version:}

B. Deltort. Experimental and numerical aspects of adiabatic shear in a 4340 steel. Journal de Physique IV Proceedings, 1994, 04 (C8), pp.C8-447-C8-452. 10.1051/jp4:1994869 . jpa-00253430

\section{HAL Id: jpa-00253430 https://hal.science/jpa-00253430}

Submitted on 1 Jan 1994

HAL is a multi-disciplinary open access archive for the deposit and dissemination of scientific research documents, whether they are published or not. The documents may come from teaching and research institutions in France or abroad, or from public or private research centers.
L'archive ouverte pluridisciplinaire HAL, est destinée au dépôt et à la diffusion de documents scientifiques de niveau recherche, publiés ou non, émanant des établissements d'enseignement et de recherche français ou étrangers, des laboratoires publics ou privés. 


\title{
Experimental and numerical aspects of adiabatic shear in a 4340 steel
}

\author{
B. Deltort( $(1)$
}

DGA/ETCA/CREA, 16 bis Avenue Prieur de la Côte d'Or, 94114 Arcueil, France

Résumé: La localisation de la déformation sous forme de bandes de cisaillement adiabatique est étudiée, lors d'essais de torsion dynamique, avec une nouvelle géométrie d'éprouvette.

L'introduction d'un défaut géométrique contrôlé, sous la forme d'une réduction de l'épaisseur permet ainsi l'étude précise de la localisation en fonction de la taille du défaut.

Parallèlement, des simulations numériques monodimensionnelles avec un modèle explicite, utilisant une loi de comportement thermo-visco-plastique ont été réalisées. Une faible différence existe entre la simulation et l'expérience, due à l'existence de défauts métallurgiques ou d'irrégularités sur la surface non pris en compte dans le modèle.

\begin{abstract}
Shear localization is analysed in dynamic torsion test with a new specimen design. The appearance of localized deformation is governed by the size of the initial defect in the sample. The defect consists of a small thickness reduction around the middle of the sample.

An explicit model is used, based on the resolution of the governing thermo-mechanical equations, with heat transfer. The small difference that exists between the simulations and experiments is due to the metallurgical and surface defects, neither of which is accounted for in the model.
\end{abstract}

\section{Introduction}

Adiabatic shear is a localization phenomenon that is commonly observed in many materials subjected to high strain rates. The resulting structure after failure is a set of very narrow and severely deformed bands, often less than $50 \mu \mathrm{m}$ wide. The term "adiabatic shear" covers a number of complex mechanical and thermal phenomena that are indistinguishable from each other. However, a simple interpretation can be proposed to describe the process leading to the appearance of these bands. On the basis of the first analysis of Zenner and Hollomon [1], starting with a local increase in the deformation at a point of inhomogeneity or structural defect in the material, one can assume a local increase in the temperature due to plastic work. If the loading time is short, the temperature increase is greater than the thermal leak through conduction. This rise in temperature reduces the local mechanical characteristics of the material, which again favors deformation on the same site. The cycle thereby described is selfcatalytic and rapidly leads to the ruin of the structure.

The interpretation presented in figure 1 emphasizes the importance of the initial defect where the localization occurs. In simulations, Molinari and Clifton [2] and Anand et al. [3] use such a defect in the initial structure to initiate the localization. Also, Duffy [4] experimentally points out the effect the specimen shape defect has on the instant of severe localization. 


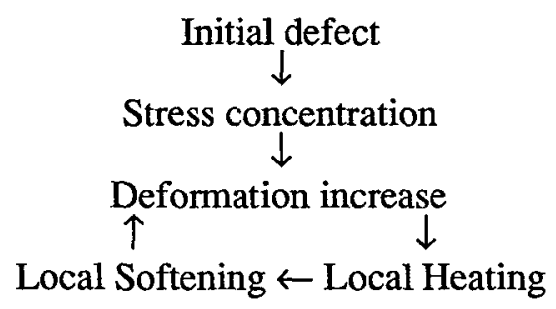

Figure 1 : Self-catalytic ruin cycle

The purpose of this investigation was to understand and model the effect of a geometric defect on the localization. Three steps were necessary:

- exact determination of the material's thermo-visco-plastic properties,

- creation of adiabatic shear bands in an appropriate specimen,

- full simulation of simple shear by an explicit model.

\section{Experimental methods}

\subsection{Materials}

The experimental investigation is performed on AISI 4340 steel (AFNOR 35 NCD 16) having the chemical composition given in table 1 .

\begin{tabular}{|c|c|c|c|c|c|c|c|c|}
\cline { 2 - 8 } \multicolumn{1}{c|}{} & $\mathrm{C}$ & $\mathrm{Si}$ & $\mathrm{Mn}$ & $\mathrm{S}$ & $\mathrm{P}$ & $\mathrm{Ni}$ & $\mathrm{Cr}$ & $\mathrm{Mo}$ \\
\hline$\%$ & 0.374 & 0.38 & 0.39 & 0.003 & 0.012 & 3.83 & 1.72 & 0.30 \\
\hline
\end{tabular}

Table 1 : AISI 4340 steel nominal composition (in w\%)

The cast-in-vacuo steel was supplied in the form of bars of $20 \mathrm{~mm}$ diameter. After an austenizing heat treatment at $875^{\circ} \mathrm{C}$ in a vaccum for minutes, and quenching in gaseous nitrogen, a tempering heat treatment is performed at $600^{\circ} \mathrm{C}$ for 30 minutes.

The constitutive equation has been identified by an inverse technique on more than 20 tests carried out simultaneously, for which three different compressive tests were required:

- quasi-static isothermal tests $\left(\dot{\varepsilon}<0.01 \mathrm{~s}^{-1}\right)$,

- quasi-static adiabatic tests $\quad\left(0.1<\dot{\varepsilon}<10 \mathrm{~s}^{-1}\right)$,

- dynamic adiabatic tests $\quad\left(100<\dot{\varepsilon}<8000 \mathrm{~s}^{-1}\right)$.

The quasi-static tests were performed on a hydraulic testing machine, and the dynamic tests on a Hopkinson bar set-up.

The identification procedure consists in the minimization of the difference between each point of each experiment and in a thermo-mechanical simulation of each compression test. In the quasi-static isothermal tests, the identification used the stress parameter alone. For the quasi-static adiabatic tests, it was possible to measure the temperature rise with a thermocouple soldered to the specimen. Under such conditions, the identification used the stress and the temperature parameters. Lastly, for the dynamic tests, it was difficult to measure the rise in temperature experimentally. On the other hand, this rise which reduces the material's characteristics, has been taken into account in the simulation (full coupled thermomechanical model). The system to be solved in all of the configurations is represented by the constitutive equations (1) and the energy balance (2) below ( $\beta$ being the Taylor Quinney coefficient $\approx 0.9$, $T$ temperature (K), $\bar{\sigma} \dot{\bar{\varepsilon}}_{p l}$ plastic work $\left(\mathrm{Pa} . \mathrm{s}^{-1}\right), \rho$ density $\left(\mathrm{kg} \cdot \mathrm{m}^{-3}\right), C_{p}$ heat capacity $\left.\left(\mathrm{J} . \mathrm{kg}^{-1} \cdot \mathrm{K}^{-1}\right)\right)$.

$$
\bar{\sigma}=\sigma_{0} \underbrace{\left(k+\ln \left(1+\frac{\bar{\varepsilon}_{p l}}{\varepsilon_{0}}\right)\right)}_{\text {strain hardening }} \underbrace{\left(1+a T+b T^{2}+c T^{3}\right)}_{\text {thermal softening }} \underbrace{\left(1+\left(\frac{\dot{\bar{\varepsilon}}_{p l}}{D}\right)^{1 / p}\right)}_{\text {viscosity }}
$$




$$
\dot{T}=\beta \frac{\bar{\sigma} \dot{\bar{\varepsilon}}_{p l}}{\rho C_{p}}
$$

The coefficients used in the model were identified by optimizing (minimizing) the difference between the model and the experimental points (through an inverse optimization method). Figure 2,3 and 4 represent the experimental measurements and calculations assuming the model after identification. Also, as the material does not exhibit von Mises plasticity, static torsional tests had to be performed. Moreover, the temperature range identified was too restricted at first. The effect of the temperature was identified over a broader range $\left(0^{\circ} \mathrm{C}\right.$ to $700^{\circ} \mathrm{C}$ ) by further testing (Deltort [5]). The coefficients obtained are then given in table $2(\mathrm{~T}$, in $\mathrm{K})$.

\begin{tabular}{|c|c|c|c|c|c|c|c|c|}
\cline { 2 - 8 } \multicolumn{1}{c|}{} & $\bar{\sigma}_{0} 10^{+9}$ & $k$ & $\varepsilon_{0} 10^{-9}$ & $a 10^{-3}$ & $b 10^{-6}$ & $c 10^{-9}$ & $p$ & $D$ \\
\hline Compression & 0.090487 & 0.3338 & 0.1904 & 2.304 & 4.15 & -2.67 & 2.4286 & 2124427.3 \\
\hline Torsion & 0.04148 & 2.4097 & 0.04460 & 2.304 & 4.15 & -2.67 & 2.4286 & 3679616.0 \\
\hline
\end{tabular}

Table 2 : Values of the coefficients in the constitutive equation

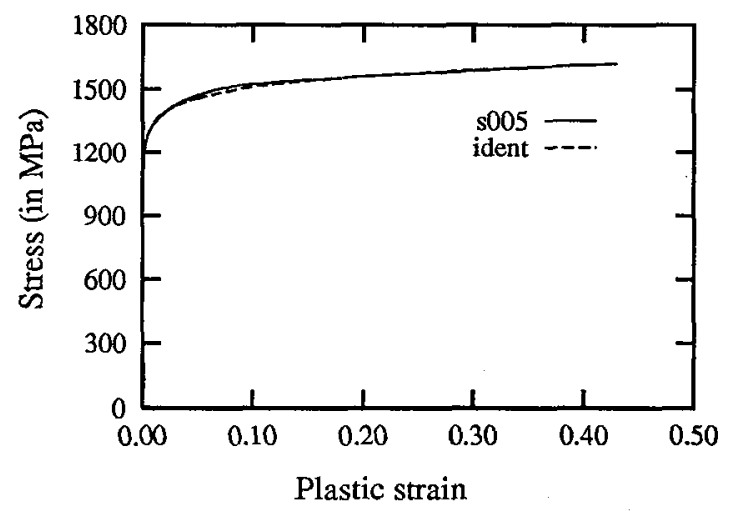

Figure 2 : Quasi-static isothermal test $10^{-3} \mathrm{~s}^{-1}$ (stress)
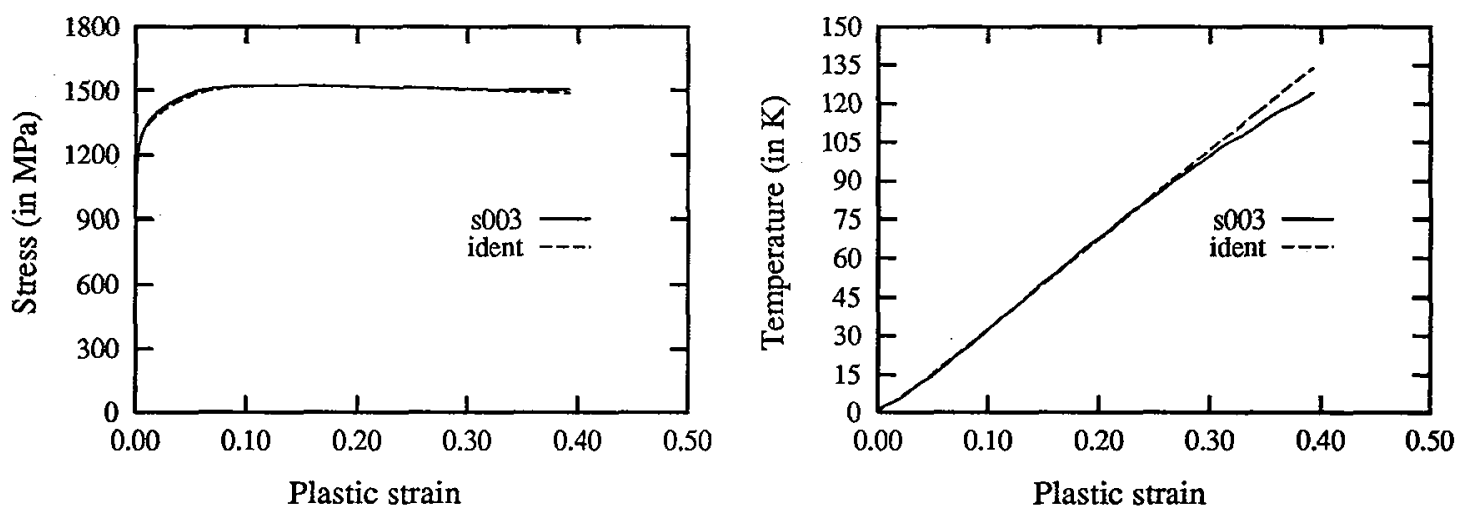

Figure 3 : Quasi-static adiabatic test $1 \mathrm{~s}^{-1}$ (stress and temperature) 

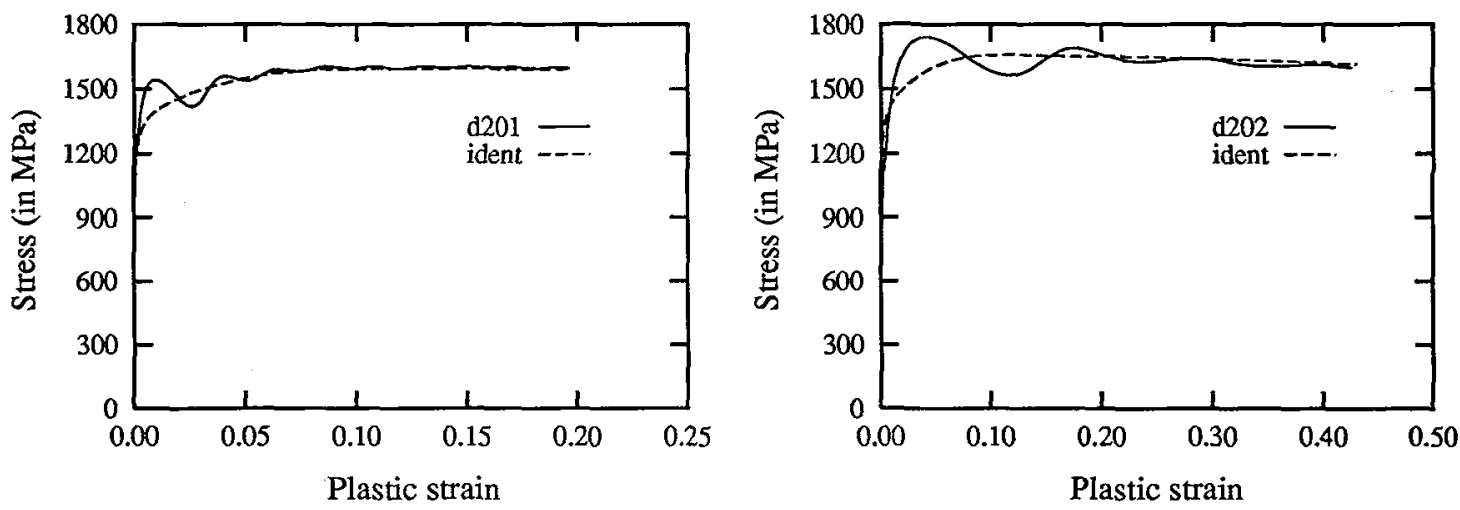

Figure 4 : Dynamic tests $1500 \mathrm{~s}^{-1}$ and $7000 \mathrm{~s}^{-1}$ (stress)

\subsection{Torsional test specimen}

The defect introduced is a very small reduction (of less than $20 \mu \mathrm{m}$ ) in the thickness in the middle of the specimen. Figure 5 represents the resulting geometry.

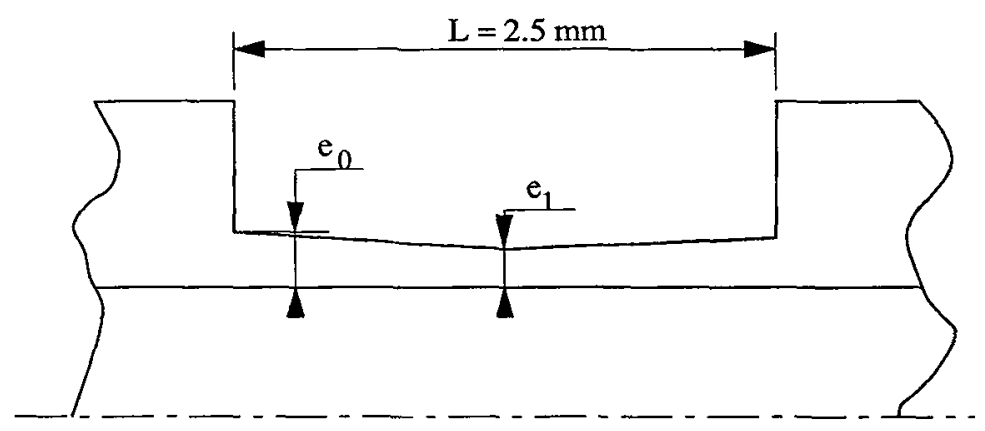

Figure 5 : Test specimen geometry with defect

The tool used to cut the defect is the same, so that the surface of the specimen across the defect is always the same. The defect size is determined only by the depth of the cut $\left(\tilde{\varepsilon}=\frac{e_{0}-e_{1}}{e_{0}}\right)$. Five defect sizes were tested $(\tilde{\varepsilon}=3.3 \%-4.0 \%-5.0 \%-6.6 \%-10 \%)$ The instant of severe localization is then highly reproducible, for a given defect size.

\section{Problem formulation}

To represent the torsion tests, a semi-infinite plate simple shear model was used (figure 6). The equations giving the properties of a plate of variable thickness are given by Batra and Kim [6].

The equations obtained are then the following:

$$
\frac{\partial(e \tau)}{\partial y}=e \frac{\partial^{2} x}{\partial t^{2}}
$$

momentum balance 
$\gamma=\frac{\partial y}{\partial x} \quad \gamma=\gamma_{e l}+\gamma_{p l} \quad \gamma_{e l}=\frac{\tau}{\mu} \quad$ elastic and plastic parts

If $\tau>f\left(\gamma_{p l}\right) g(T)$ then $\tau=f\left(\gamma_{p l}\right) g(T) h\left(\dot{\gamma}_{p l}\right)$

else $\tau=\mu \gamma_{e l}$

$e \beta \tau \frac{\partial \gamma_{p l}}{\partial t}=e \rho C_{p} \frac{\partial T}{\partial t}-k \frac{\partial\left(e \frac{\partial T}{\partial y}\right)}{\partial y}$

energy balance

(6)

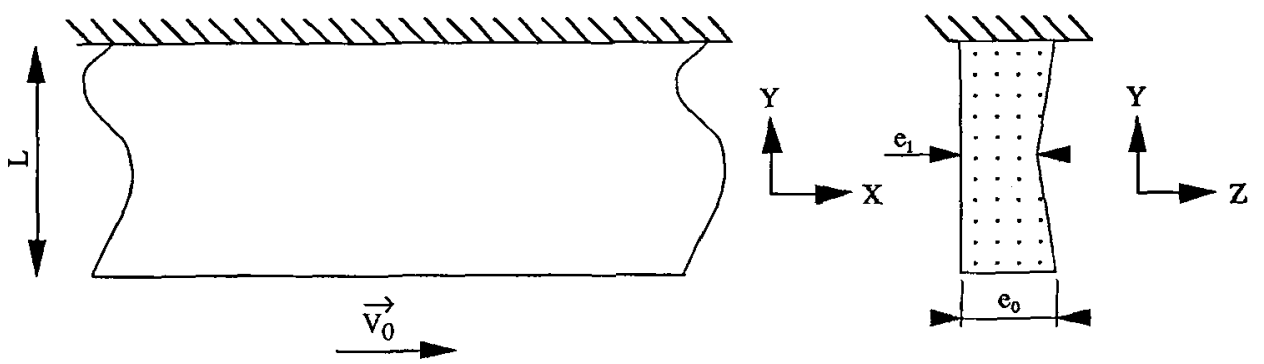

Figure 6 : Modeling of a plate in simple shear

The momentum balance equation is given by relation (3), in which the thickness varies with y. Below $50000 \mathrm{~s}^{-1}$, which is the case here, Deltort [5] showed it was not necessary to take the effect of inertia into account. Assuming this, equation (3) then reduces to $\frac{\partial(\mathrm{e} \tau)}{\partial y} \equiv 0$. Moreover, the spatial discretization step is not constant, in order to get a good resolution at the center of the specimen, where the strain localizes.

One major parameter to be defined is the point in time when the localization begins. Yet it is not possible to define this time precisely, to the extent that the phenomenon is a continuous one. We must then adopt a definition such as the strain at $80 \%$ of the maximum ( figure 7 ).

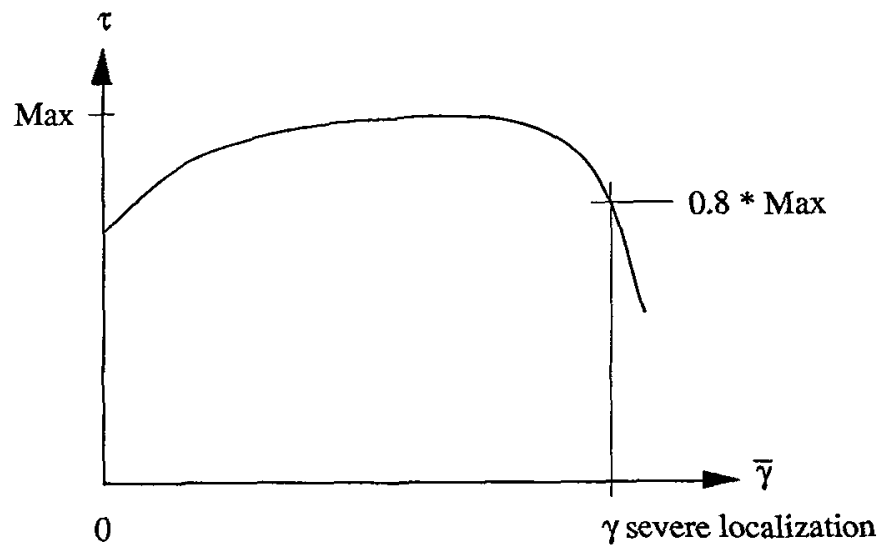

Figure 7 : Definition of severe localization 


\section{Discussion and results}

With the definition given in previous section, it is possible to compare the experiments performed with specimens having a thickness reduction, and with simulations. Figure 8 shows the strain with severe localization as a function of the defect introduced.

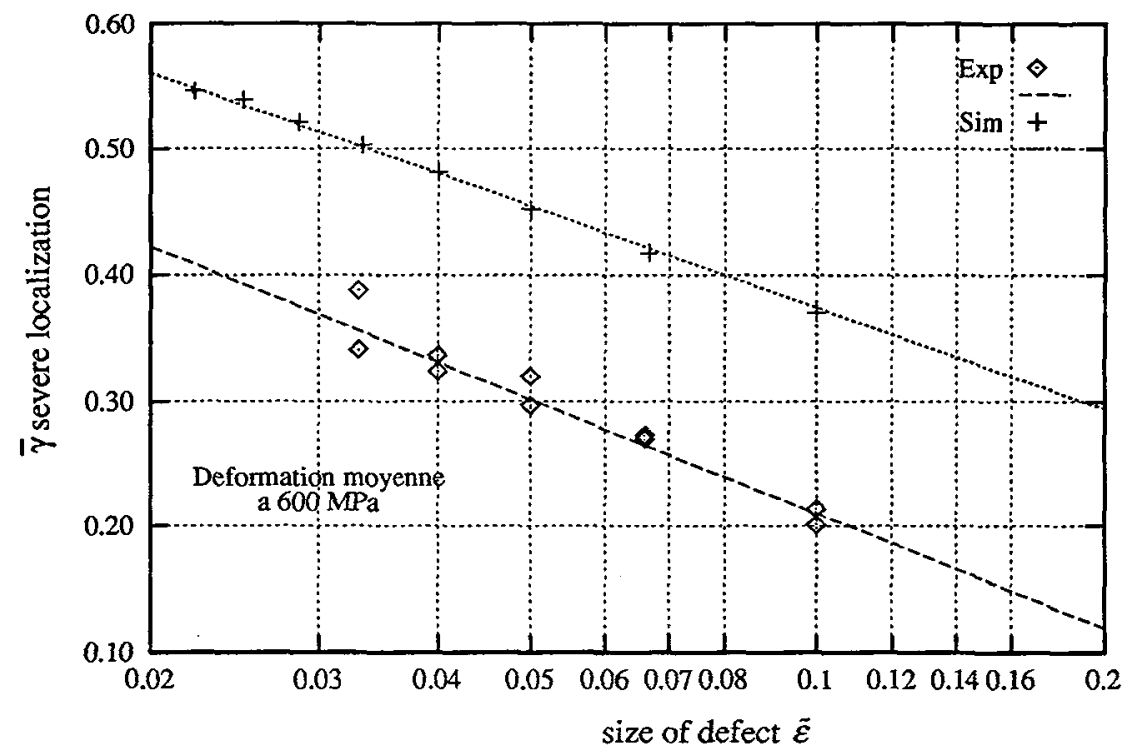

Figure 8 : Comparison of simulation and experiments

A slight difference appears between the model used and the experiments performed with the specimen having a geometric defect. Several possibilities may be considered to explain this difference :

- one dimensional representation of a three dimensional phenomenon,

- 5\% uncertainty in the coefficients in the constitutive equation, resulting in a variation of more than $20 \%$ in the severe localization strain,

- lastly, neither the metallurgical defects existing within the material nor the surface imperfections of the machining are accounted for in the model. These ignored defects do have a tendency to localize the strain more quickly.

\section{Conclusion}

The new test specimen geometry allows precise investigation of localization as a function of the defect used. A simple relation appears between the size of the defect and the severe localization deformation. A full constitutive equation defined by an inverse technique can be used to simulate the localization precisely.

\section{References:}

[1] C. ZENNER et J.H. HOLLOMON, J. of Physique, Vol. 15, pp. 22, 1944

[2] A. MOLINARI and R.J. CLIFTON, J. Appl. Mech.,Vol. 5, pp. 806, 1987

[3] L. ANAND, K.H. KMM and J.G. SHAWKI, J. Mech. Phys. Solids, Vol. 35, pp. 407, 1987

[4] J. DUFFY, J. of Physique, C3-645, 1991

[5] B. DELTORT, Thesis of École Nationale Supérieure des Mines de PARIS, 1993

[6] R.C BATRA et C.H. KIM, Int. J. of Engi. of Science, Vol. 29, n 8, pp. 949, 1991 